\title{
Changes in Levels of Serum and Urinary Collagen-Related Substances in Growth Hormone Deficient Children Following Discontinuation of Growth Hormone Therapy
}

\author{
TATEO KUNO, AND SUMio MIYAZAKI \\ Department of Pediatrics, Saga Medical School, Saga 849-8501, Japan
}

THE effect of GH on bone formation and resorption in vivo has been reported recently [1, 2]. We reported that urinary pyridinoline excretion rapidly decreased in patients with GH deficiency when the administration of $\mathrm{GH}$ was stopped, and then concluded that exogenous $\mathrm{GH}$ appears to stimulate bone resorption in those patients [3]. In order to further clarify the effect of $\mathrm{GH}$ on collagen metabolism, we herein examined changes in the levels of another four types of collagen-related substances.

\section{Subjects and Methods}

We studied 26 patients, 21 males and 5 females, aged 5 to 16 years, with complete or partial GH deficiency. They had been treated with $0.5 \mathrm{IU} /$ $\mathrm{kg}$ / week of GH in 6-7 divided doses, for periods of one to five years. 16 male patients and all the female patients were prepubertal and the rest were at the pubertal stage. In particular, all who showed an increase of $6 \mathrm{~cm}$ a year or more in growth velocity during the first year of $\mathrm{GH}$ administration compared to before it, had been prepubertal during their first year of treatment. All patients had open metaphyses. After informed consent was obtained, early morning urine and serum specimens were collected while the patients received GH and then

Correspondence to: Dr. Tateo KUNO, Department of Pediatrics, Saga Medical School, Nabeshima, Saga 8498501, Japan

Key words: Hydroxyproline, Prolylhydroxylase, Type III procollagen propeptide, Type IV collagen, GH for 14 days after discontinuing it.

Total urinary hydroxyproline was assayed by high-performance liquid chromatography with a cation-exchange column. Serum specimens were assayed for both prolylhydroxylase (EC 1.14.11.2) and type IV collagen with solid-phase enzyme immunoassay kits provided by Daiichi Pure Chemicals Co. Ltd., Tokyo, Japan, and for type III procollagen propeptide with a solid-phase immunoradiometric assay kit provided by CIS Bio International, Gif-sur-Yvette Cedex, France.

\section{Results}

Total urinary hydroxyproline excretion levels corrected for creatinine were $169 \pm 8.3 \mathrm{mmol} / \mathrm{mol}$ creatinine (mean $\pm \mathrm{SEM}$ ) during $\mathrm{GH}$ administration and $145 \pm 6.4 \mathrm{mmol} / \mathrm{mol}$ creatinine (mean \pm SEM) after discontinuation of $\mathrm{GH}$. Wilcoxon signed-rank test showed a significant decrease in total urinary hydroxyproline excretion levels after discontinuation of GH $(P<0.005)$. Fig. 1A shows the relationship between the increase in growth velocity during the first year of $\mathrm{GH}$ administration compared to before it, and the ratio of the levels of urinary hydroxyproline while receiving $\mathrm{GH}$ and after discontinuation. Linear regression analysis revealed no significant relationshipship $(P=0.19)$. Levels of serum prolylhydroxylase also significantly decreased from $76.9 \pm 2.6 \mathrm{ng} / \mathrm{ml}$ to $63.7 \pm 3.2 \mathrm{ng} /$ $\mathrm{ml}$ in 14 days after discontinuing therapy $(P<0.005)$. Fig. 1B shows the relationship between the increase in growth velocity and the ratio of the levels of serum prolylhydroxylase while receiving $\mathrm{GH}$ and 

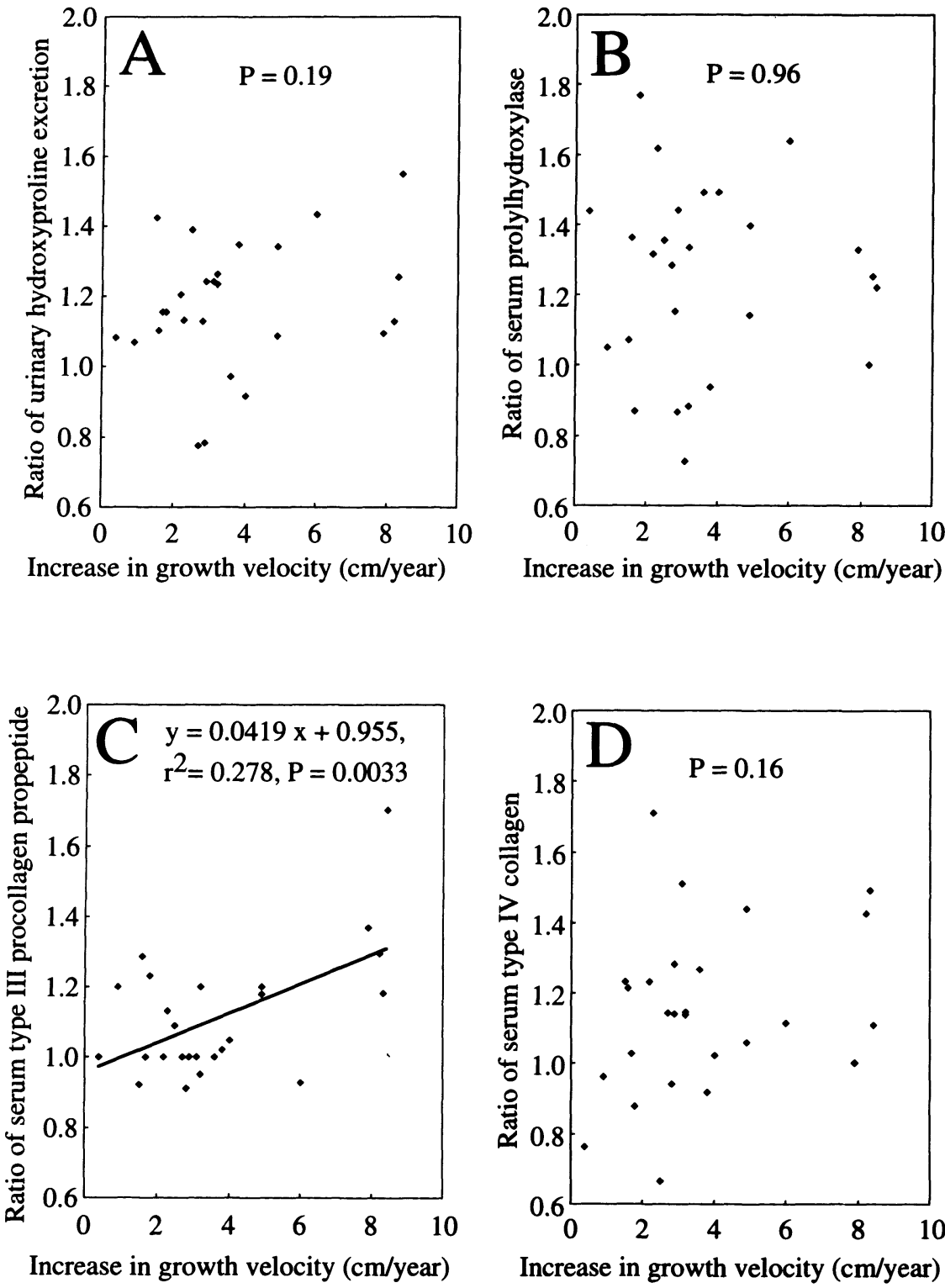

Fig. 1. A: Relationship between the increase in growth velocity during the first year of $\mathrm{GH}$ administration compared to before it, and the ratio of urinary hydroxyproline excretion levels corrected for creatinine while receiving $\mathrm{GH}$ and for 14 days after discontinuation. B: Relationship between the increase in growth velocity and the ratio of serum prolylhydroxylase levels while receiving $\mathrm{GH}$ and for 14 days after discontinuation. C: Relationship between the increase in growth velocity and the ratio of serum type III procollagen propeptide levels while receiving $\mathrm{GH}$ and for 14 days after discontinuation. D: Relationship between the increase in growth velocity and the ratio of serum type IV collagen levels while receiving $\mathrm{GH}$ and for 14 days after discontinuation.

after discontinuation. No significant regression was found between them $(P=0.96)$. Levels of serum type III procollagen propeptide also significantly decreased from $1.36 \pm 0.075 \mathrm{ng} / \mathrm{ml}$ to $1.24 \pm 0.071$ $\mathrm{ng} / \mathrm{ml}$ in 14 days after discontinuing therapy $(P<0.025)$. Fig. $1 C$ shows the relationship between the increase in growth velocity and the ratio of the levels of serum type III procollagen propeptide 
while receiving $\mathrm{GH}$ and after discontinuation. A significant positive correlation was seen in the linear regression analysis $\left(r^{2}=0.278, P=0.0033\right)$. Levels of serum type IV collagen also significantly decreased from $5.20 \pm 0.22 \mathrm{ng} / \mathrm{ml}$ to $4.65 \pm 0.21 \mathrm{ng} / \mathrm{ml}$ in 14 days after discontinuing therapy $(P<0.01)$. Fig. 1D shows the relationship between the increase in growth velocity and the ratio of the levels of serum type IV collagen while receiving $\mathrm{GH}$ and after discontinuation. No significant regression was found between them $(P=0.16)$. In addition, linear regression analyses were calculated between the peak value of $\mathrm{GH}$ in arginine-loading test or insulin hypoglycemia test, and each of the ratio of the levels of the above four substances while receiving GH and after discontinuation. No significant regression was found between them.

\section{Discussion}

As shown above, the levels of the four types of collagen-related substances were increased while receiving GH. Only the effects of GH on type III procollagen propeptide have been reported [4]. The ratios of levels of the four types of substances while receiving $\mathrm{GH}$ compared to levels after discontinuation shown above are thought to represent the degree of activation of collagen metabolism by the exogenous GH. A significant positive correlation was observed between the increase in growth velocity and the ratio of levels of serum type III procollagen propeptide (Fig. 1C). Thus, exogenous GH seems to stimulate type III procollagen propeptide in patients with $\mathrm{GH}$ deficiency. In prepubertal subjects, the increase in growth velocity during the first year of $\mathrm{GH}$ administration compared to before it is thought to be inversely correlated with the patients' endogenous GH secretion [5]. Therefore, it is possible that the degree of activation of type III procollagen propeptide, as well as urinary pyridinoline excretion [3], by exogenous $\mathrm{GH}$ is inversely correlated to patients' endogenous $\mathrm{GH}$ secretion. Another three types of substances also seemed to be weakly stimulated by exogenous $\mathrm{GH}$. Exogenous $\mathrm{GH}$ is considered to activate collagen metabolism in osteoblasts and osteoclasts and in the whole-body extracellular matrix. The action on collagen metabolism may be mostly mediated by insulin-like growth factor I, but also may be in part due to the action of GH itself on the liver or fibroblasts [6]. The ratio of levels of serum type III procollagen propeptide provides informations about patients' endogenous GH secretion, which may not be completely clarified by pharmacological provocation tests performed before receiving $\mathrm{GH}$.

\section{References}

1. Kanzaki S, Hosoda K, Moriwake T, Tanaka H, Kubo T, Inoue M, Higuchi J, Yamaji T, Seino Y (1992) Serum propeptide and intact molecular osteocalcin in normal children and children with GH deficiency: A potential marker of bone growth and response to GH therapy. J Clin Endocrinol Metab 75: 1104-1109.

2. Fujimoto S, Kubo T, Tanaka M, Miura M, Seino $Y$ (1995) Urinary pyridinoline and deoxypyridinoline in healthy children and in children with $\mathrm{GH}$ deficiency. J Clin Endocrinol Metab 80: 1922-1928.

3. Kuno T, Tasaki H, Miyazaki S, Horie H (1997) Rapid decrease of urinary pyridinoline excretion in $\mathrm{GH}$ deficient children following discontinuation of $\mathrm{GH}$ therapy. Acta Paediatr Jpn 39: 18-20.

4. Lindstedt G, Weijkum L, Lundberg PA (1984) Serum procollagen-III as indicator of therapeutic effect in children treated for somatropin deficiency. Clin Chem 30: 1879-1880.

5. Brook CGD, Hindmarsh PC, Smith PJ (1989) The management of short stature. In: Brook CGD (ed) Clinical Paediatric Endocrinology, 2nd ed, Blackwell Scientific Publications, Oxford, 122-123.

6. Murphy LJ, Vrhovsek E, Lazarus L (1983) Identification and characterization of specific growth hormone receptors in cultured human fibroblasts. J Clin Endocrinol Metab 57: 1117-1120. 